Supplement of Earth Syst. Dynam., 7, 953-968, 2016

http://www.earth-syst-dynam.net/7/953/2016/

doi:10.5194/esd-7-953-2016-supplement

(c) Author(s) 2016. CC Attribution 3.0 License.

(c) (i)

Earth System
Dynamics

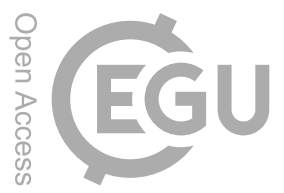

Supplement of

\title{
Deforestation in Amazonia impacts riverine carbon dynamics
}

Fanny Langerwisch et al.

Correspondence to: Fanny Langerwisch (langerwisch@pik-potsdam.de)

The copyright of individual parts of the supplement might differ from the CC-BY 3.0 licence. 

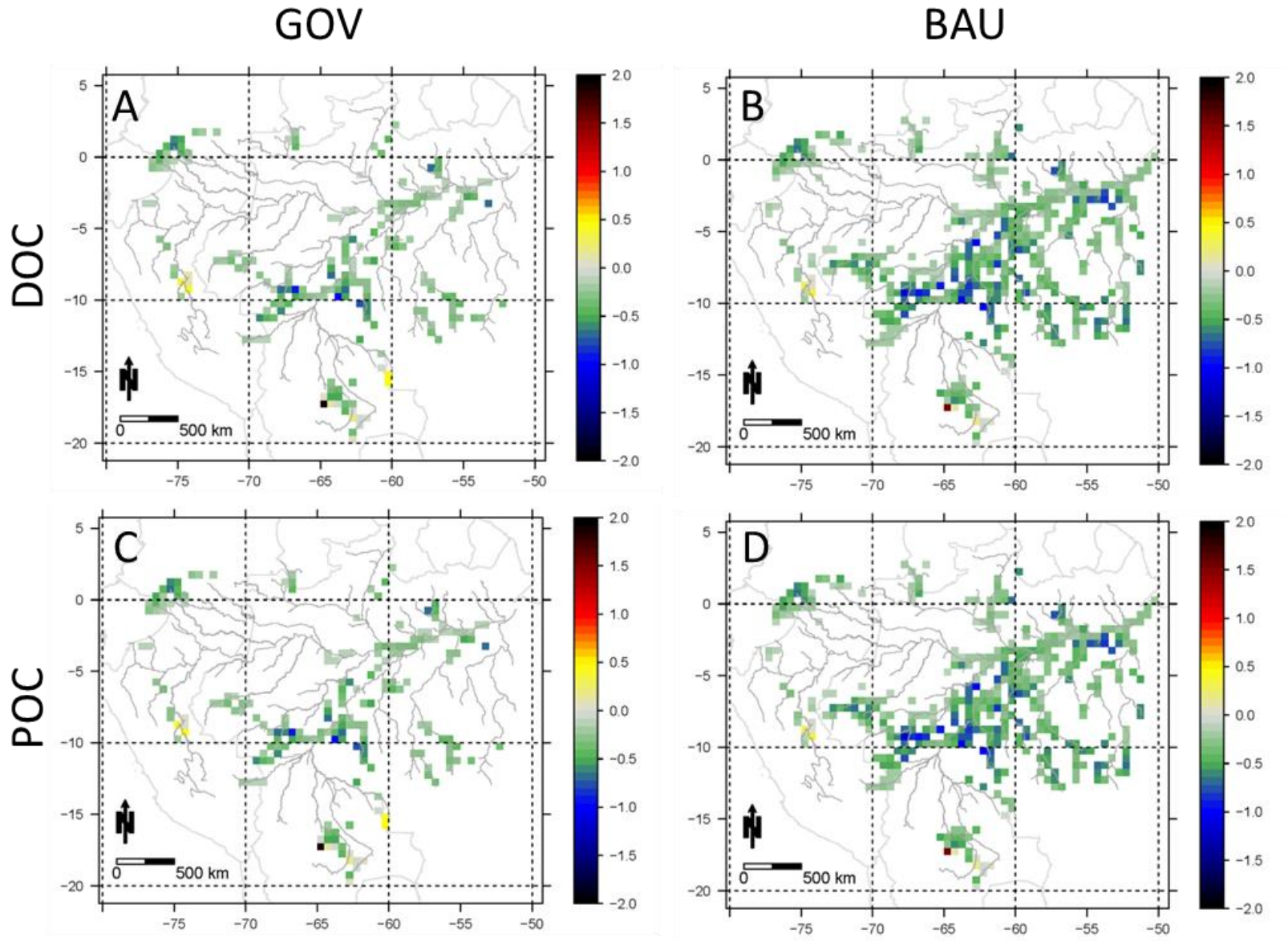

Figure S1: Similar change in dissolved $(\mathrm{A}, \mathrm{B})$ and particulate organic carbon $(\mathrm{C}, \mathrm{D})$ due to deforestation. SRES scenario is A1B, climate model is MPI-ECHAM5. Positive values (yellow and red) indicate a gain and negative values (green and blue) indicate a loss in carbon caused by deforestation (GOV and BAU). Only cells with significant changes $(\mathrm{p}<0.05$, Wilcoxon Rank Sum Test) are shown. 

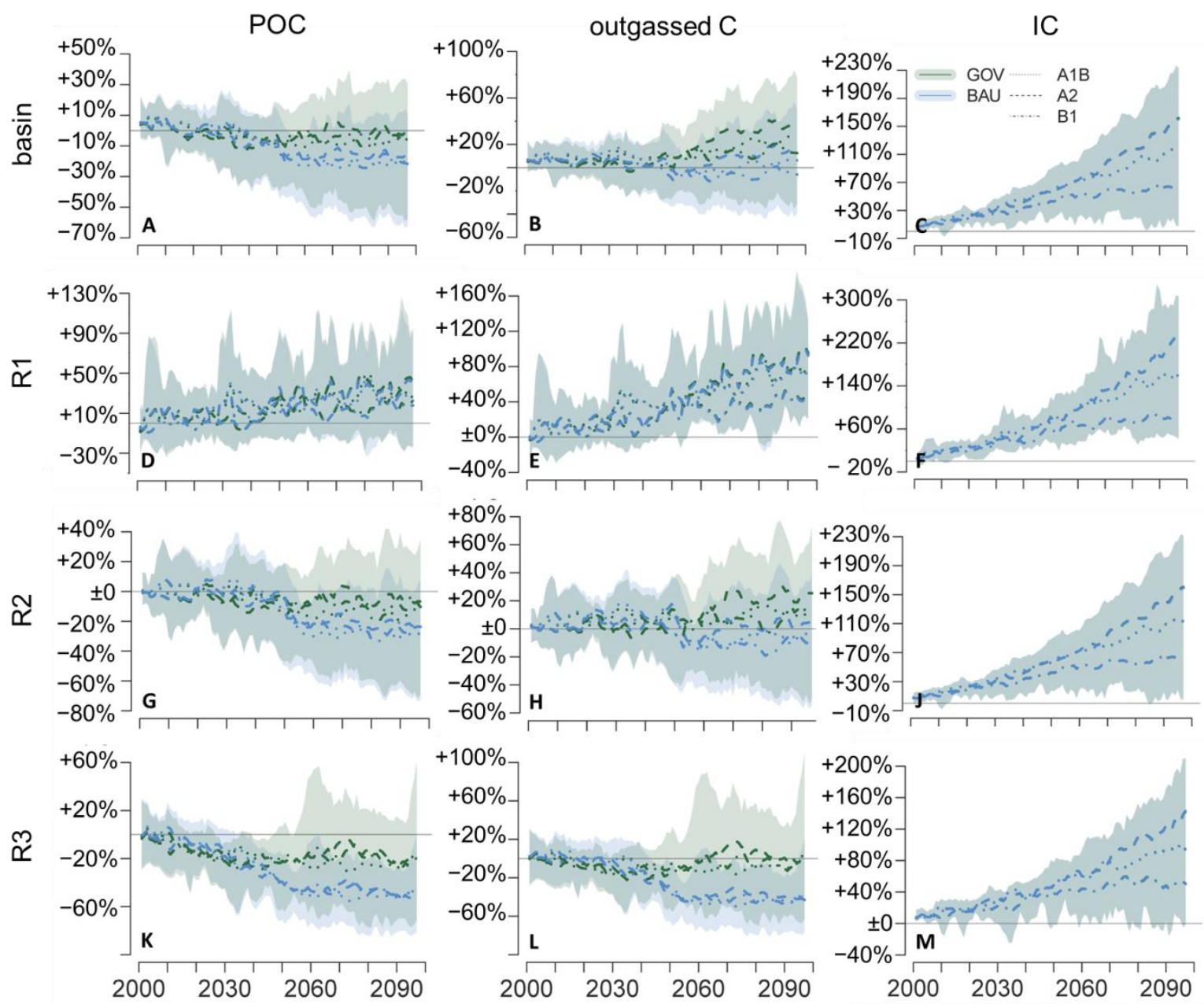

30 Figure S2: Temporal change in riverine organic carbon due to the combination of 31 climate and land use change. Change of annual sum of carbon in the deforestation scenario (GOV or BAU) compared to the NatVeg scenario (average over 1971-2000) for the whole basin (A-C) and the three sub-regions (R1-R3; D-M) as 5-year-mean for GOV (green) and BAU (blue), representing $\mathrm{E}_{\mathrm{CCDefor}}$. The shaded areas indicate the full range of values of all five climate models. Bold lines represent the 5-year-mean of the five climate models. 